\title{
An assessment of trends in the use of the IUD in Ghana: National results dissemination and utilization
}

Ivy Osei

John Gyapong

Monica Wanjiru

Population Council

Ian Askew

Population Council

Follow this and additional works at: https://knowledgecommons.popcouncil.org/departments_sbsr-rh

Part of the Demography, Population, and Ecology Commons, International Public Health Commons, and the Women's Health Commons How does access to this work benefit you? Let us know!

\section{Recommended Citation}

Osei, Ivy, John Gyapong, Monica Wanjiru, and lan Askew. 2005. "An assessment of trends in the use of the IUD in Ghana: National results dissemination and utilization," FRONTIERS Final Report. Washington, DC: Population Council. 


\title{
An Assessment of Trends in the Use of the IUD in Ghana: \\ National Results Dissemination and Utilization
}

\author{
Ivy Osei and John Gyapong \\ Health Research Unit, Ghana Health Service \\ Monica Wanjiru and Ian Askew \\ Population Council, Kenya
}

January 2005

This study was funded by the US AGENCY FOR INTERNATIONAL DEVELOPMENT (USAID) under the terms of the Frontiers in Reproductive Health Cooperative Agreement Number HRN-A-00-98-00012-00, and Subagreement Number AI03.69A. The opinions expressed herein are those of the authors and do not necessarily reflect the views of USAID. 


\section{Table of Contents}

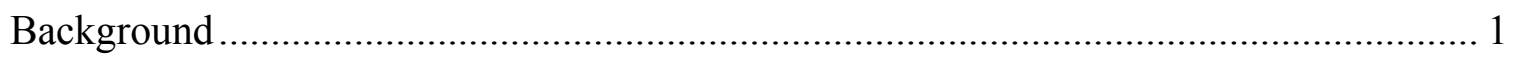

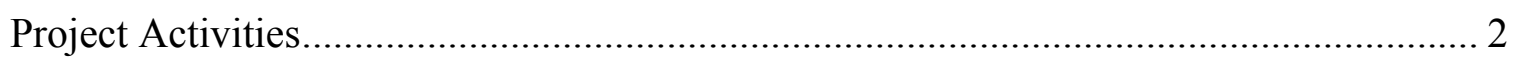

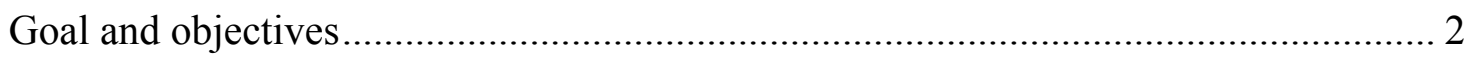

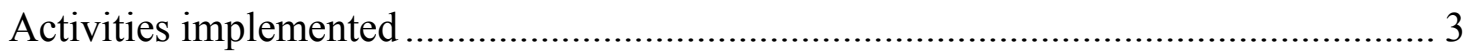

Issues raised for follow-up and recommendations: ................................................ 4

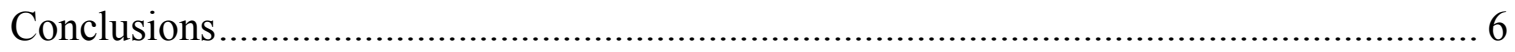

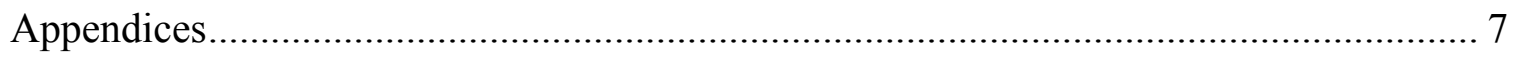

Attendance at Dissemination Meetings ................................................................... 7

Persons contacted in service delivery organizations............................................ 11 


\section{Background}

The IUD is a safe and reversible contraceptive method that requires little effort on the part of the user once inserted and offers up to 10 years of protection against pregnancy. It is also the most cost-effective method of reversible contraception currently available. Despite these advantages, the use of the IUD in relation to other contraceptive methods is reported to have either stagnated or declined in a number of countries, including Ghana. Given the lack of understanding of the reasons why IUD use in Ghana has stagnated, and may well have declined, a study was conducted in 2003 by the Ghana Health Service (GHS) and the Frontiers in Reproductive Health Program (FRONTIERS) to answer the following key questions:

- What client characteristics affect the demand for and use of the IUD?

- What are the provider and system characteristics that shape use of the IUD?

- What can be done to reduce barriers to the use of the IUD?

The overall aim of the study was to inform GHS, USAID, and other partners involved in providing family planning services in Ghana about future directions that could be taken to reinvigorate the IUD within the context of a family planning service based on the principles of free and informed choice. The Health Research Unit (HRU) conducted the study, with technical assistance from FRONTIERS and funding from USAID ${ }^{1}$.

The findings showed that the declining interest in and use of the IUD as a family planning method could be attributed to several factors. These include negative perceptions and false beliefs about the method, the physical design of the technology, and fear of weight loss associated with its use. Other barriers apparently impeding IUD use are insufficient pro-active demand creation for the method and an insufficient number of providers with practical experience of insertion and removal. Contrary to the findings in other countries where IUD use is low, this study found that providers in Ghana generally had favourable attitudes towards the product and were not biased against it in favour of other methods.

The study recommended that:

- Increasing awareness of the IUD as a family planning option should be intensified through multiple strategies. These could include branding and actively marketing the product and using the testimonies of satisfied clients to dispel misperceptions and demystify the technology. The Ghana Life Choices Program was identified as one possible mechanism through which this may be achieved.

- An IUD-focused training program needs to be developed that builds not only technical skills but also skills in raising awareness about the IUD during consultations with new and revisiting family planning clients, particularly with those clients for whom the IUD

\footnotetext{
Gyapong, John, Gifty Addico, Ivy Osei, Mercy Abbey, Dominic Atweam Kobinah, Henrietta Odoi Agyarko, Gloria Quansah Asare, Harriet Birungi, and Ian Askew. 2003. "An assessment of trends in the use of the IUD in Ghana," FRONTIERS Final Report. Washington, DC: Population Council.
} 
may be an appropriate method. A strategy should then be devised and implemented to create a critical mass of trained and experienced IUD providers strategically located throughout the country.

- Clients should be informed about the ease and cost-effectiveness of using the IUD, including that it is a one-visit only method (plus check-up), in contrast to the more popular hormonal contraceptives (injectable or pill) that require multiple visits and are more costly to use.

- The GHS should review the National Reproductive Health Service Protocols to clarify the guidelines on the type of provider who is qualified to insert the IUD and the eligibility criteria for potential users, particularly with regard to nulliparous and HIV-infected women.

These findings and their implications were discussed at a national dissemination meeting for reproductive health stakeholders held in Accra in November 2002. A written report and brief summary were published, and at least one paper is to be published in a peer-reviewed journal.

Given the importance attached by the GHS and its partners to re-invigorating the IUD as a contraceptive option, a request was made that the findings from this study be disseminated to the district level of the health care system and funding be obtained from USAID to support further dissemination activities. This report covers the activities carried out in the first half of 2004, which also included reaching out to other family planning organizations in the country with a view to encouraging them to use the results in their own programs.

\section{Project Activities}

\section{Goal and objectives}

The goal of this project was to contribute to expanding the choice of contraceptive methods available to individuals and couples in Ghana.

The specific objectives were to:

- Assist the Reproductive and Child Health Unit (RCHU) to devise messages that could be used to encourage family planning providers and family planning clients to consider the IUD as an option when choosing a contraceptive method.

- Summarize the key findings and programmatic recommendations from the research study and from other relevant literature in a format appropriate for communicating with district level health staff.

- Inform district and regional level health care providers about the IUD as an alternative contraceptive choice for certain individuals and couples in Ghana through zonal level meetings. 
- Make available appropriate educational materials that could be used during routine family planning consultations to facilitate further dissemination of this information to the lowest level of family planning providers.

- Provide assistance to the RCHU, the Ghana Life Choices Program, and other relevant organizations in developing strategies to use this information for strengthening both the demand for and supply of the IUD.

- Document plans developed for utilization of results by service organizations after exposure to this information, and document examples of best practices used in Ghana related to the study findings that might be useful for other Ghanaian providers in expanding access to the IUD.

\section{Activities implemented}

\section{A. Development of an informational package on the IUD}

Through access to recent literature on the IUD and participation in the USAID-supported InterAgency Working Group on Increasing Access to the IUD, FRONTIERS facilitated the acquisition of a series of informational briefs entitled "Expanding Women's Choices through a Balanced and Sustainable Contraceptive Method Mix: A New Look at IUCDs." The Ministry of Health in Kenya developed these briefs with technical support from Family Health International (FHI). Staff from HRU and RCHU of the Ghana Health Service met to review and discuss the briefs and agreed to adapt them to the Ghanaian situation for distribution to and use by service providers and program managers. HRU and RCHU staff put together a Ghanaian version of the briefs that incorporated the current WHO revised eligibility criteria for IUD and IUD use in HIV-positive clients. The draft was circulated to stakeholders for comments that were incorporated into the final document. The Ghanaian version of the informational briefs on the IUD is currently being distributed by the RCHU to service providers for use in their routine service delivery.

\section{B. Zonal dissemination meetings to reach district level health personnel}

Meetings were held to discuss the findings with representatives of various service providers with the objective of informing them of the findings, reviewing the programmatic implications of these findings, and strengthening their support for enhancing the IUD's role within a range of contraceptive methods. The meetings brought together the regional and district coordinators and supervisors of reproductive health services, IUD trainers, private providers, and health managers within each zone. These representatives were encouraged to disseminate the findings further among their staff and were given summaries and copies of the study report to support this cascade dissemination. Staff from RCHU and HRU conducted the meetings (see Appendix).

The Southern and Northern zonal meetings were held on 24 February and 2 March 2004, respectively. The Southern Zone includes Greater Accra, Eastern, Western, and Volta regions while the Northern comprises Northern, Upper West, and Upper East regions. The Middle zonal meeting was held on the 1 April 2004 and covered Ashanti, Brong Ahafo, and Central Regions. 
Dr. Ivy Osei from the HRU presented the study findings at the meetings, followed by a discussion of policy and programmatic implications led by Dr. Gloria Quansah Asare, the National Family Planning Program Manager. The meetings then prioritized actions that would increase awareness of and access to the IUD.

Additionally, the study findings were presented and discussed at a meeting with IUD Trainers in February 2004 and at the biannual workshop for service providers in March 2004. Both meetings were organized by the RCHU. Copies of the study report were distributed to all the regions. Regions made requests for more copies of the report.

\section{Issues raised for follow-up and recommendations}

Discussions focused on strategies for promotion of the IUD and improving service delivery.

- $\quad$ Promoting the IUD and intensifying client education on IUD: At all three meetings it was agreed that there was a need to intensify education on the IUD at the community level. Satisfied clients could be used to target clients who have negative preconceived ideas about the IUD.

- Improving counselling skills: Providers should be helped to improve their counselling skills. It is imperative to focus on benefits, side effects, and misconceptions about the IUD.

- Improving service delivery: Several issues were raised that need to be addressed to improve service delivery.

\section{$\checkmark$ Selection of providers for training}

Participants felt that managers should select providers with midwifery skills for family planning training where they are available, because of the technical competency required. They also reasoned that, in the long-term, community health officers (CHOs) in the $\mathrm{CHPS}^{2}$ initiative could be given special intensified training to perform IUD insertions. This may help to reduce the problem of lack of staff at periphery facilities. Other participants expressed apprehension about the CHOs since they are perceived to be overburdened and may do things that go beyond their mandate, thereby compromising the CHPS concept. There was a suggestion that female medical assistants could also be trained to provide IUD services.

\section{$\checkmark$ Equipment and IEC materials}

Providers were advised to be proactive in requesting equipment and IEC materials from their managers and the medical stores.

The Community-based Health Planning and Services (CHPS) Initiative seeks to make basic health care services accessible to all Ghanaians by making effective use of both health sector and community resources. The program consists of re-orienting and redeploying community health nurses from static clinics to live in the underserved communities and provide primary health care to the community under the designation "Community Health Officers". 
$\checkmark$ STI/HIV risk and IUD use

The WHO 2004 revised eligibility criteria were discussed. Participants were informed that HIV and high risk HIV are category 2 conditions for IUD use. For category 2 conditions, the method can generally be used, but careful follow-up may be needed. Participants were apprehensive about this new position; this means there is the need for more education on the revised eligibility criteria. It is hoped that the information briefs will assist in this direction. The contraceptive updates organized by the RCHU for family planning providers should highlight these changes.

$\checkmark$ Difficulty in removal

Participants emphasized that to increase provider confidence in IUD service provision, IUD insertion training should also focus on removal techniques as providers often encounter clinical difficulties in removal. This may influence their desire to provide the IUD to an eligible client. Clients may also face difficulties when they desire to remove the IUD because providers sometimes lack the confidence to perform a removal.

- At all three meetings it was agreed that that there was need for improved counselling to highlight both positive and negative aspects of the IUD. Strategies suggested include:

$\checkmark$ Use of flip charts and visual aids during client counselling to allay client fears.

$\checkmark$ Actively involve males in education and counselling. Male nurses could be trained to reach out to the men.

$\checkmark$ Community Health Officers (CHOs) should be encouraged to talk about family planning, including the IUD, at the community level.

$\checkmark$ Satisfied clients should also be used to inform others about the advantages of the IUD in their communities.

$\checkmark$ Other family planning service providers, such as private practitioners and pharmacists, should be encouraged to participate in promoting all family planning methods.

$\checkmark$ District Assemblies could be encouraged to provide logistic support and undertake social mobilization to assist service provision.

Supportive supervision should also be intensified.

\section{Assisting service delivery organizations to utilize this information}

In order for the IUD to become more widely recognized as having a role to play in expanding the contraceptive choices available to Ghanaians, the key findings from the initial assessment of trends in IUD use recommended that at least three activities be pursued: 
- Among couples and individuals practising family planning, increase awareness of the IUD as a cost-effective and safe contraceptive option.

- Enable providers to include balanced messages about the IUD when counselling family planning clients.

- Ensure that there are a sufficient number of strategically located providers able to counsel, insert, and remove the IUD so that users can be easily cared for or referred for the service.

The RCHU and HRU identified the following key service delivery organizations: Ghana Social Marketing Foundation (GSMF), Planned Parenthood Association of Ghana (PPAG), and John Hopkins University (JHU). Individual meetings with the organizations were held to ascertain their interest and capacity to develop and undertake such activities. Copies of the study report were made available. Although JHU was identified for this purpose, they closed their operations in the country. Both GSMF and PPAG see increased use of the IUD as part of their activities and therefore would like to take the idea further. However, they would need to study the report within their organizations before any further action is undertaken

- GSMF

A discussion was held with the programme manager for HIV/AIDS and Family Planning, who indicated that the GSMF already had programmes that promote all family planning products, including the IUD. Recently they have started a sales promotion campaign that targets private service providers, and she indicated that in two months the sale of IUD has increased five-fold.

- PPAG

An initial contact has been made with the Director of Programmes, who indicated that promoting all family planning methods is part of their core function. Therefore, they would study the document and decide on the next steps before taking action.

\section{Conclusions}

Through the zonal level meetings, district and regional level health care providers have been updated about the IUD as an alternative contraceptive choice for individuals and couples in Ghana. To facilitate further dissemination of updates on the IUD, a summary of key findings and programmatic recommendations from the research study and information from other literature have been put together to assist family planning providers at all levels in their work.

Two service delivery organizations in the country have been contacted to ascertain their interest and capacity to develop and undertake activities that will increase awareness about the IUD. Both organizations see raising awareness about the IUD as an important part of their activities and therefore would like to take their ideas further. 


\section{Appendices}

\section{Attendance at dissemination meetings}

A. Southern Zone

\begin{tabular}{|c|c|}
\hline Name & Organization \\
\hline $\begin{array}{l}\text { Dr. Ivy Osei } \\
\text { Dr John Gyapong } \\
\text { Bertha Garshong } \\
\text { Edith Wellington } \\
\text { Margaret Gyapong }\end{array}$ & Health Research Unit (HRU) \\
\hline $\begin{array}{l}\text { Dr. Gloria Quansah Asare } \\
\text { Gladys Kankam } \\
\text { Patricia Odoi } \\
\text { Gladys Kankam }\end{array}$ & Reproductive and Child Health Unit (RCHU) \\
\hline $\begin{array}{l}\text { Jane Wickstrom } \\
\text { Aduonum Darko } \\
\text { Ben Tvereh }\end{array}$ & USAID \\
\hline \multicolumn{2}{|l|}{ Greater Accra Region } \\
\hline $\begin{array}{l}\text { Dora Abbosey } \\
\text { Gloria Amuah } \\
\text { Patience Dodoo } \\
\text { Comfort Antwi } \\
\text { Joana Bepoe } \\
\text { Juliana Lamptey } \\
\text { Grace Appiah Owusu } \\
\text { Nancy Akrong } \\
\text { Barbara Acquay } \\
\text { Rosemary Martei } \\
\text { Margaret Lartey } \\
\text { Sarah Mensah } \\
\text { Emelia Thompson }\end{array}$ & $\begin{array}{l}\text { PHN, Ga district } \\
\text { PHN, Kpeshie District } \\
\text { PHN, Osu Klottey District } \\
\text { PHN, Mamprobi Polyclinic } \\
\text { PHN, Dansoman Health Centre } \\
\text { PHN, Regional Health Directorate } \\
\text { PHN, Ussher Polyclinic } \\
\text { PHN, Dangme West } \\
\text { PHN, Kaneshie Polyclinic } \\
\text { PHN, Accra Metro Health Directorate } \\
\text { PHN, Dangme East } \\
\text { PHN, Tema Municipal Health Administration } \\
\text { PHN, Adabraka Polyclinic }\end{array}$ \\
\hline \multicolumn{2}{|l|}{ Volta Region } \\
\hline $\begin{array}{l}\text { Gloria Makafui Ahorlu } \\
\text { Charity Kugblenu } \\
\text { Vivian Tettevi } \\
\text { Florence A. Obrusuh } \\
\text { Diana Gbeckor- Kove } \\
\text { Success Nelly Sika Doulo } \\
\text { Millicent Kokui Heloo } \\
\text { Doris Quame } \\
\text { Augusta Doe } \\
\text { Justine Alornyo } \\
\text { Theresa Bruku }\end{array}$ & $\begin{array}{l}\text { PHN, Kpando District } \\
\text { PHN, Hohoe District } \\
\text { PHN, Kadjebi District } \\
\text { PHN, Jasikan District } \\
\text { PHN, North Tongu } \\
\text { PHN, Keta District } \\
\text { PHN, Aflao District } \\
\text { PHN, Regional Health Directorate } \\
\text { PHN, Regional Health Directorate } \\
\text { PHN, South Tongu } \\
\text { PHN, Akatsi District }\end{array}$ \\
\hline
\end{tabular}




\begin{tabular}{|l|l|}
\hline Western Region & \\
\hline Dr. Linda Vanotoo & District Director of Health, Shama Ahanta East \\
Anna Ekuma Essandoh & PHN, Aowin Suaman District \\
Perpetual Djan & PHN, Mpohor Wassa East Distirct \\
Doris Lartey & PHN, Bibiani-Anh-Bekwai District \\
Helen Botchway & PHN, Sefwi Wiaso District \\
Anna Agbotui & Regional Public Health Nurse \\
Hannah Addo & PHN, Nzema East District \\
Gifty Tagoe & PHN, Wassa West District \\
Vivian Oppong & PHN, Wassa Amenfi District \\
Lucy Adzigbli & PHN, Shama Ahanta East District \\
Jemima Akoto & Private Midwife \\
Jemima Crentsil & Private Midwife \\
Charlotte Danquah & PHN, Jomoro District \\
Ruth Biyimba & PHN, Ahanta West District \\
\hline \multicolumn{2}{|l|}{} \\
\hline Eastern Region & SMO (PH) \\
\hline Dr Emmanuel Tinkorang & District Director of Health \\
Dr. Nana Konama Kotey & Regional Public Health Nurse \\
Patience Afua Quashigah & PHN, Koforidua Municipal Health Directorate \\
Gladys Oware & \\
\hline
\end{tabular}

B. Northern Zone

\begin{tabular}{|l|l|}
\hline Northern Region & Health Research Unit (HRU) \\
\hline Dr. Ivy Osei & Reproductive and Child Health Unit (RCHU) \\
\hline $\begin{array}{l}\text { Dr. Gloria Quansah Asare } \\
\text { Gladys Kankam }\end{array}$ & \\
\hline Dr. Akwasi Twumasi & Senior Medical Officer (PH) \\
Dr. Kofi Issah & District Director of Health (Savelugu) \\
Sophia Mahama & PHN, Gambuzi \\
Fulera Goodman & Private Midwife, Tamale \\
Joana Quarcoe & PHN, Saboba/Chere \\
Elizabeth Tigaa & PHN, Bole \\
Balchisu Dason & Regional Public Health Nurse \\
Cosmos Alhassan & PHN, Regional Training Coordinator \\
Victoria Okai & PHN, East Mamprusi \\
Maria Ayichuru & PHN, Yendi \\
Susana Kumah & PHN, Savelugu/Nanton \\
Rosine Ayishetu Mahama & PHN, Tamale Municipality \\
Braimah Ramatu & PHN, Damongo \\
Ayishetu Bukari & PHN, Bimbilla \\
Kate Dery & PHN, Zabzugu/Tatale \\
Catherine Mwine & PHN, TKD \\
Khadita Issah & CHN, Yapei \\
\hline
\end{tabular}




\begin{tabular}{|l|l|}
\hline Florence Seidu & Mankarigu \\
Mariama Mahama Lucy & Bawena \\
Jinche Abudu & Mpaha \\
Memuna Issifu & Busunu \\
Rose Tambro & Private Midwife \\
Juliana Tansebla & Kalba \\
Kate Mumuni & Gindabo \\
Ayi Issah & Bamboi \\
Esther Konlan & Jimbale \\
Victoria Aboyella & Nalerigu \\
Vivian Yiddi & Nalerigu \\
Regina Siebebale & West Gonja Hospital \\
Halun Abdulai & Gbintri \\
Evelyn Mori & Damongo \\
Naomi Siba & Nakpaduri \\
Hajara Yakubu & Bole \\
Maria Ziblim & Bamboi \\
\hline Upper East Region & PHN, Bawku East \\
\hline Beatrice Ateyoro & PHN, Bolgatanga \\
Victoria Navro & PHN, Bawku West \\
Margaret Bawah & PHN, Bawku West \\
Evelyn Adda & PHN, Bolgatanga \\
Bibiana Yizura & PHN, Sandema \\
Juliana Adiake & PHN, Salaga \\
Sukeina Salami & PHN, Private Midwife, Tamale \\
Mariama Yakubu &
\end{tabular}

\section{IUD Trainers Meeting}

\begin{tabular}{|l|l|}
\hline \multicolumn{2}{|l|}{ IUD Trainers } \\
\hline $\begin{array}{l}\text { Dr. Gloria Quansah Asare } \\
\text { Gladys Kankam }\end{array}$ & Reproductive and Child Health Unit (RCHU) \\
\hline Mercy Offei & Clinical Instructor, Korle Bu Teaching Hospital \\
Perfect Bleboo & IUD Trainer, RCHU \\
Modesta L. Badu & Clinical Instructor, Koforidua Regional Hospital \\
Martha Appiagyei & Nurses Training College, Koforidua \\
Georgette E. Tengabo & Nurses Training College, Tamale \\
Agartha Molbila & Community Health Nurses Training School, Tamale \\
Grace Asomaning & Midwifery Training School, Kumasi \\
Cynthia Bruce Smith & Clinical Instructor, Komfo Anokye Teaching Hospital \\
Gladys Kankam & IUD Trainer, RCHU \\
Patricia Odoi & RCHU \\
Dr. Gloria Quansah & Family Planning Program Manager, RCHU \\
Comfort Adams & National Aids Control Program \\
Patricia Darko & EngenderHealth \\
\hline
\end{tabular}




\begin{tabular}{|l|l|}
\hline Mary Dampson & Public Health Nurses School, Accra \\
Gudecn Hodjih & Headquarters, Ghana Health Service \\
\hline
\end{tabular}

D. Middle Zone

\begin{tabular}{|l|l|}
\hline Ashanti Region & Health Research Unit (HRU) \\
\hline Dr. Ivy Osei & Reproductive and Child Health Unit (RCHU) \\
\hline Dr. Gloria Quansah Asare & \\
Gladys Kankam & Regional Director of Health \\
\hline Dr. Kofi Asare & Senior Medical Officer (PH) \\
Dr. Kyei Faried & Principal Nursing Officer \\
Anna Ofori & Regional Health Directorate, RCHU \\
Augustina Apea & Regional Health Directorate, RCHU \\
Agnes Nkumfo & \\
B.A. Yakubu & \\
Esther Amedzro & \\
Alice Mensah & \\
Anna Adamah & \\
Mary Wilson & \\
Lydia Amu & \\
Dominic Dobbin & \\
Marian Frimpong & \\
Rita Anafu & \\
Henrietta C. Fuglo & \\
Joana Burgesson & \\
Rebecca T. Dokumyu & \\
Eatrice Adjei & \\
Lydia Owusu Ansah & \\
Vida Araba Eshun & \\
Patricia Adabie & \\
Juliana Nuako & \\
Chriastina Aidoo & \\
Vesta Ayordia & \\
Hellen Aovare & \\
Leticia Ayeh-Diabene & \\
Allswell Ackon & \\
Theresa Otua-Achempong & \\
Dora Atia & \\
\hline Brong Ahafo Region & \\
\hline Dr. Asemanyi- Mensah & \\
Alice Vorleto & \\
Winifred Tienaah & \\
Margaret Aboligu & \\
Susana Acheampong & \\
Martha Larbi Agyenfra & \\
Bazaabon Paulina & \\
& \\
\end{tabular}




\begin{tabular}{|l|l|}
\hline Priscilla A. Baiden & \\
Mary Amoateng & \\
Veronica A. Tortoe & \\
Dorothy Gyinae & \\
Judith Addoquaye & \\
Veronica Gyan & \\
Monica Kantor-Mensah & \\
Salamatu Ibrahim & \\
\hline Central Region & \\
\hline Mary Araba Fosu & \\
Margaret Asuam & \\
Trinity Brown & \\
Lorinda Tetteh & \\
Faustina Kargbe & \\
Adelaide Dravie & \\
Margaret Sampson & \\
Margaret Forson & \\
Barbara Boachie & \\
Grace Okine & \\
\hline
\end{tabular}

Persons contacted in service delivery organizations

\begin{tabular}{|l|l|l|}
\hline Name & Position/Rank & Organization \\
\hline Francis Yankey & Director of Programmes & PPAG \\
\hline Mabel Tibu Nyarko & $\begin{array}{l}\text { Programme Manager, } \\
\text { HIV/AIDS and Family } \\
\text { Planning }\end{array}$ & GSMF \\
& & \\
\hline
\end{tabular}

